Article

\title{
Antimicrobial Activity of Chamomile Essential Oil: Effect of Different Formulations
}

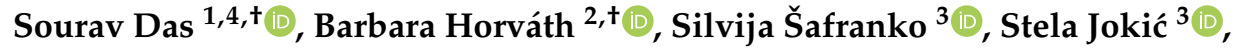 \\ Aleksandar Széchenyi ${ }^{2}$ (D) and Tamás Köszegi ${ }^{1,4, *}$ \\ 1 Department of Laboratory Medicine, Faculty of Medicine, University of Pécs, H-7624 Pécs, Hungary; \\ pharma.souravdas@gmail.com \\ 2 Institute of Pharmaceutical Technology and Biopharmacy, Faculty of Pharmacy, University of Pécs, H-7624 \\ Pécs, Hungary; barbara.horvath@aok.pte.hu (B.H.); szechenyi.aleksandar@gytk.pte.hu (A.S.) \\ 3 Faculty of Food Technology Osijek, University of Osijek, Franje Kuhaca 20, 31000 Osijek, Croatia; \\ silvija.safranko@ptfos.hr (S.Š.); stela.jokic@ptfos.hr (S.J.) \\ 4 János Szentágothai Research Center, University of Pécs, H-7624 Pécs, Hungary \\ * Correspondence: koszegi.tamas@pte.hu; Tel.: +36-72-501-500 (ext. 29249) \\ + These authors contributed equally to this work.
}

Academic Editor: Igor Jerković

Received: 31 October 2019; Accepted: 21 November 2019; Published: 26 November 2019

\begin{abstract}
Essential oils (EOs) are highly lipophilic, which makes the measurement of their biological action difficult in an aqueous environment. We formulated a Pickering nanoemulsion of chamomile EO $\left(\mathrm{C}_{\mathrm{Pe}}\right)$. Surface-modified Stöber silica nanoparticles $(20 \mathrm{~nm})$ were prepared and used as a stabilizing agent of $\mathrm{C}_{\mathrm{Pe}}$. The antimicrobial activity of $\mathrm{C}_{\mathrm{Pe}}$ was compared with that of emulsion stabilized with Tween $80\left(\mathrm{C}_{\mathrm{T} 80}\right)$ and ethanolic solution $\left(\mathrm{C}_{\mathrm{Et}}\right)$. The antimicrobial effects were assessed by their minimum inhibitory concentration $\left(\mathrm{MIC}_{90}\right)$ and minimum effective $\left(\mathrm{MEC}_{10}\right)$ concentrations. Besides growth inhibition $(\mathrm{CFU} / \mathrm{mL})$, the metabolic activity and viability of Gram-positive and Gram-negative bacteria as well as Candida species, in addition to the generation of oxygen free radical species (ROS), were studied. We followed the killing activity of $C_{P e}$ and analyzed the efficiency of the EO delivery for examined formulations by using unilamellar liposomes as a cellular model. $\mathrm{C}_{\mathrm{Pe}}$ showed significantly higher antibacterial and antifungal activities than $\mathrm{C}_{\mathrm{T} 80}$ and $\mathrm{C}_{\mathrm{Et}}$. Chamomile EOs generated superoxide anion and peroxide related oxidative stress which might be the major mode of action of $\mathrm{Ch}$ essential oil. We could also demonstrate that $\mathrm{C}_{\mathrm{Pe}}$ was the most effective in donation of the active $\mathrm{EO}$ components when compared with $\mathrm{C}_{\mathrm{T} 80}$ and $\mathrm{C}_{\mathrm{Et}}$. Our data suggest that $\mathrm{C}_{\mathrm{Pe}}$ formulation is useful in the fight against microbial infections.
\end{abstract}

Keywords: chamomile essential oil; Pickering emulsion; antimicrobial activity; free radical generation

\section{Introduction}

Essential oils (EOs) have been widely used in folk medicine throughout the history of humankind. The application of EOs covers a wide range from therapeutic, hygienic, and spiritual to ritualistic purposes. EOs are aromatic, volatile, lipophilic liquids extracted from different parts of plant materials such as barks, buds, flowers, fruits, seeds, and roots [1]. EOs are mixtures of complex compounds with variable individual chemical composition and concentrations that includes primarily terpenoids, like monoterpenes (C10), sesquiterpenes (C15), diterpenes (C20), acids, alcohols, aldehydes, aliphatic hydrocarbons, acyclic esters or lactones, rare nitrogen- and sulfur-containing compounds, coumarin, and homologues of phenylpropanoids [1,2]. The biological effects of EOs cover a wide range of effects, including antioxidant, antimicrobial, antitumor, anti-inflammatory, and antiviral activity [3]. 
The increase in demand for the use of aromatherapy as complementary and alternative medicine has led people to believe in the myth that EOs are harmless because they are natural and have been used for a long time [4]. However, there might be several side effects of EOs even if topical administration is applied and, among these, allergic reactions are the most frequent (many EOs can cause, e.g., rashes on the skin). Some of them can be poisonous if absorbed through the skin, breathed, or swallowed. Previous studies also report the interaction of EOs with other drugs [5]. The continuous production of new aroma chemicals and their widespread and uncontrolled usage as alternative therapies together with many carrier diluents have brought serious problems, especially among children. In this regard, it is of utmost importance to study the mode of action of essential oils and to find a proper, unharmful formulation. Another serious problem is the highly lipophilic nature of EOs, which makes it impossible to measure their biological effects in an aqueous environment $[1,6,7]$.

One major characteristic and application of EOs are their strong antimicrobial activity, including antibacterial and antifungal effects without the development of microbial resistance. Numerous studies are found in the literature describing the antimicrobial activities of a large variety of EOs [8-13]. Most of these assays include conventional broth dilution method, disk diffusion method, and bioautography assay to measure the antimicrobial activity of EOs. Efforts have been made to overcome the lipophilic nature of the oils usually by application of EOs diluted in seemingly suitable solvents/detergents. In the case of natural lipophilic volatile compounds like EOs, solvents of varying polarity, e.g., DMSO, ethanol, and methanol, are most commonly used. However, previous studies have reported the antimicrobial effects of the solvents themselves (DMSO, ethanol, and other solvents in various microbial assays) or their influence on the true antimicrobial effects of EOs [14]. The usage of solubilizing agents limits the precise determination of the antimicrobial activities of EOs. Also, a major problem might arise in the classical assays due to the evaporation of EOs during the assay or the inability of the test microbes to reach the lipophilic range of the tested EOs (in bioautography, as an example) $[15,16]$.

Therefore, new formulations have been determined to increase the solubility or to emulsify the EOs in an aqueous environment. These efforts help to stabilize the oils, to produce an even release of the active components into the required environment, and to maintain their antioxidant and antimicrobial activities $[6,11,17,18]$. Detergents and organic solvents are not welcome in this regard. Attempts have been made to entrap EOs by modified cyclodextrins for the exact determination of their antimicrobial characteristics $[19,20]$.

The application of Pickering nanoemulsion is a quite novel approach to stabilize oil-in-water $(\mathrm{O} / \mathrm{W})$ and water-in-oil (W/O) emulsions by solid particles instead of surfactants. The mechanism involves the adsorption of solid particles on the oil-water interface, causing a significant decrease in the interfacial surface tension that results in high emulsion stability [18]. Previous studies have reported decreased evaporation of EOs from $\mathrm{O} / \mathrm{W}$ emulsion of nanoparticle-stabilized formulations versus EO-surfactant systems to be a beneficial factor [21,22].

Despite the numerous existing studies on EO-Pickering emulsion, we could not find any literature data on chamomile volatile oil-nanoparticle formulation [7,23]. The main aim of the present work is to use Pickering emulsion of chamomile EO stabilized with modified Stöber silica nanoparticles and characterize its antimicrobial effect using Gram-positive and Gram-negative bacteria as well as Candida fungal species. We could demonstrate the strong antimicrobial effects of the chamomile EO-Pickering emulsion and suggest a plausible mode of action of this formulation. Experimental efforts were made to support the suggested mode of action.

\section{Results}

\subsection{Characteristics of Stöber Silica Nanoparticles}

The mean diameter, PDI value (polydispersity index), and zeta potential of modified Stöber silica nanoparticles (SNPs) were determined by dynamic light scattering (DLS), and these values were 20 $\mathrm{nm}, 0.01$, and $-21.3 \mathrm{mV}$, respectively. The size and morphology of SNPs were examined by TEM (see 
Figure 1). The size distribution obtained by DLS was confirmed by TEM, which showed that the mean diameter of silica samples was $20 \mathrm{~nm}$; they are highly monodisperse and have a spherical shape.

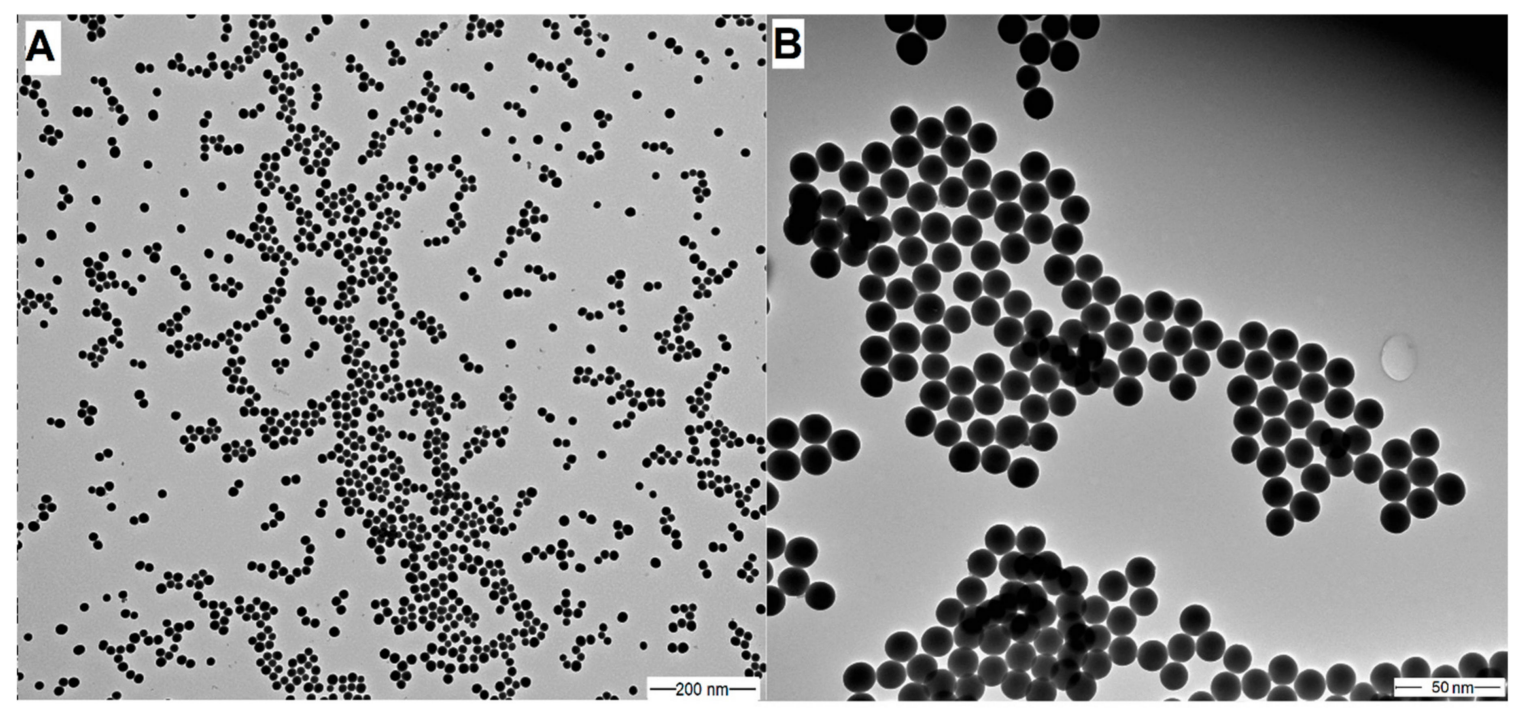

Figure 1. TEM images of silica nanoparticles (SNPs) with different resolutions: 100,000× magnification (A) and 500,000× magnification (B), accelerating voltage: $80 \mathrm{kV} ; \mathrm{d}_{\mathrm{TEM}}=20 \mathrm{~nm}$. PDI $=0.015$.

\subsection{Nanoemulsion Stability}

We have prepared a Pickering nanoemulsion with surface-modified silica nanoparticles as a stabilizing agent; the particle concentration was $1 \mathrm{mg} / \mathrm{mL}$ in every case. The chamomile EO concentration was $100 \mu \mathrm{g} / \mathrm{mL}$. To compare properties of chamomile EO-Pickering nanoemulsion $\left(\mathrm{C}_{\mathrm{Pe}}\right)$ with the conventional, surfactant-stabilized nanoemulsions, and an emulsion with the Tween 80 stabilizing agent was also prepared. The concentration of surfactant was the same as nanoparticles, $1 \mathrm{mg} / \mathrm{mL}$. The emulsions were stored at room temperature $\left(25^{\circ} \mathrm{C}\right)$.

We considered the emulsion to be stable when its droplet size does not change and sedimentation, aggregation of particles, or phase separation cannot be observed. The results show that the prepared Pickering emulsion is more stable than conventional emulsion (see Table 1). When the volume fraction of chamomile EO was very low, we assumed that all emulsions were of O/W type and this was confirmed by filter paper tests with $\mathrm{CoCl}_{2}$ and dye test with Sudan Red G.

Table 1. Parameters of Pickering nanoemulsion and conventional emulsion.

\begin{tabular}{ccc}
\hline Stabilizing Agent & $\mathbf{D}_{\text {droplet }}$ (nm) & Stability \\
\hline SNP & $290 \pm 4.5$ & 3 months \\
Tw80 & $210 \pm 10.5$ & 1 month \\
\hline
\end{tabular}

\subsection{Antibacterial and Antifungal Activities (MIC ${ }_{90}$ ) of Prepared Emulsions}

The effect of chamomile Pickering nanoemulsion, conventional emulsion, and essential oil in ethanol on the growth of some foodborne microbes and opportunistic fungi have been evaluated. The $\mathrm{C}_{\mathrm{Pe}}$ has been shown to have good antibacterial and antifungal activities ( $\mathrm{MIC}_{90}$ ) on Escherichia coli (E. coli) $(2.19 \mu \mathrm{g} / \mathrm{mL})$, Pseudomonas aeruginosa (P. aeruginosa) $(1.02 \mu \mathrm{g} / \mathrm{mL})$, Bacillus subtilis (B. subtilis) (1.13 $\mu \mathrm{g} / \mathrm{mL})$, Staphylococcus aureus (S. aureus) $(1.06 \mu \mathrm{g} / \mathrm{mL})$, Streptococcus pyogenes (S. pyogenes) $(2.45 \mu \mathrm{g} / \mathrm{mL})$, Schizosaccharomyces pombe (S. pombe) $(1.28 \mu \mathrm{g} / \mathrm{mL})$, Candida albicans (C. albicans) $(2.65 \mu \mathrm{g} / \mathrm{mL})$, and Candida tropicalis (C. tropicalis) $(1.69 \mu \mathrm{g} / \mathrm{mL})$, respectively when compared to $\mathrm{C}_{\mathrm{T} 80}$ counterpart $(P<0.01) . \mathrm{C}_{\mathrm{Pe}}$ showed antimicrobial activity on the selected microbes at an average of fourteen-fold less concentration compared with free essential oil in ethanol $\left(\mathrm{C}_{\mathrm{Et}}\right)$. Simultaneously, $\mathrm{C}_{\mathrm{Pe}}$ showed a similar antifungal 
effect as caspofungin (Cas) on Candida tropicalis. The comparative dose-response curves are shown in Figures 2 and 3 for bacteria and fungi, respectively.
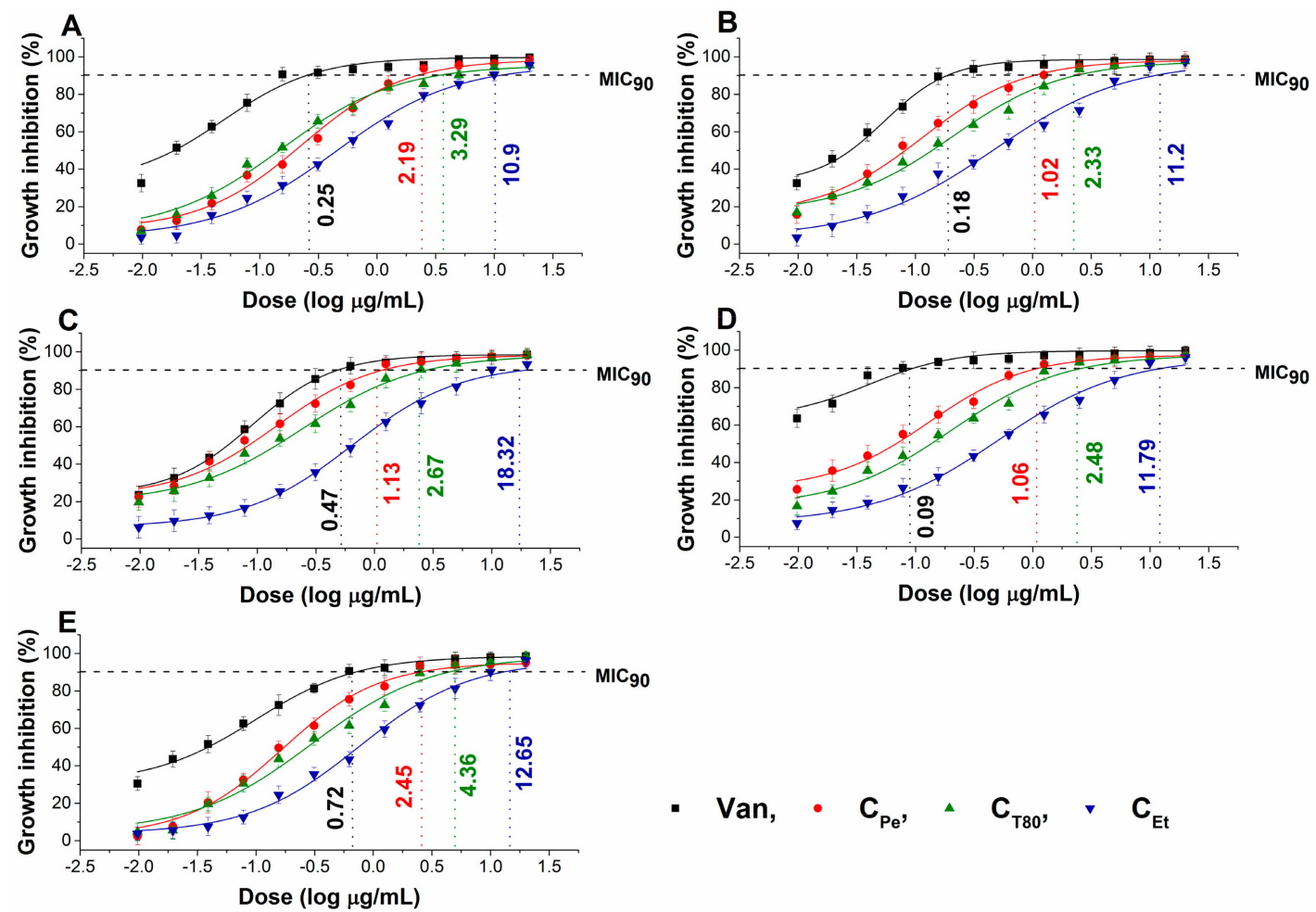

- Van, $-\mathrm{C}_{\mathrm{Pe}}, \Delta \mathrm{C}_{\mathrm{T} 80},-\mathrm{C}_{\mathrm{Et}}$

Figure 2. Minimum inhibitory concentration (MIC 90 ) of $\mathrm{C}_{\mathrm{Pe}}, \mathrm{C}_{\mathrm{T} 80}, \mathrm{C}_{\mathrm{Et}}$, and vancomycin (Van, $\mu \mathrm{g} / \mathrm{mL}$ ) on E. coli (A), S. aureus (B), B. subtilis (C), P. aeruginosa (D), and S. pyogenes (E).
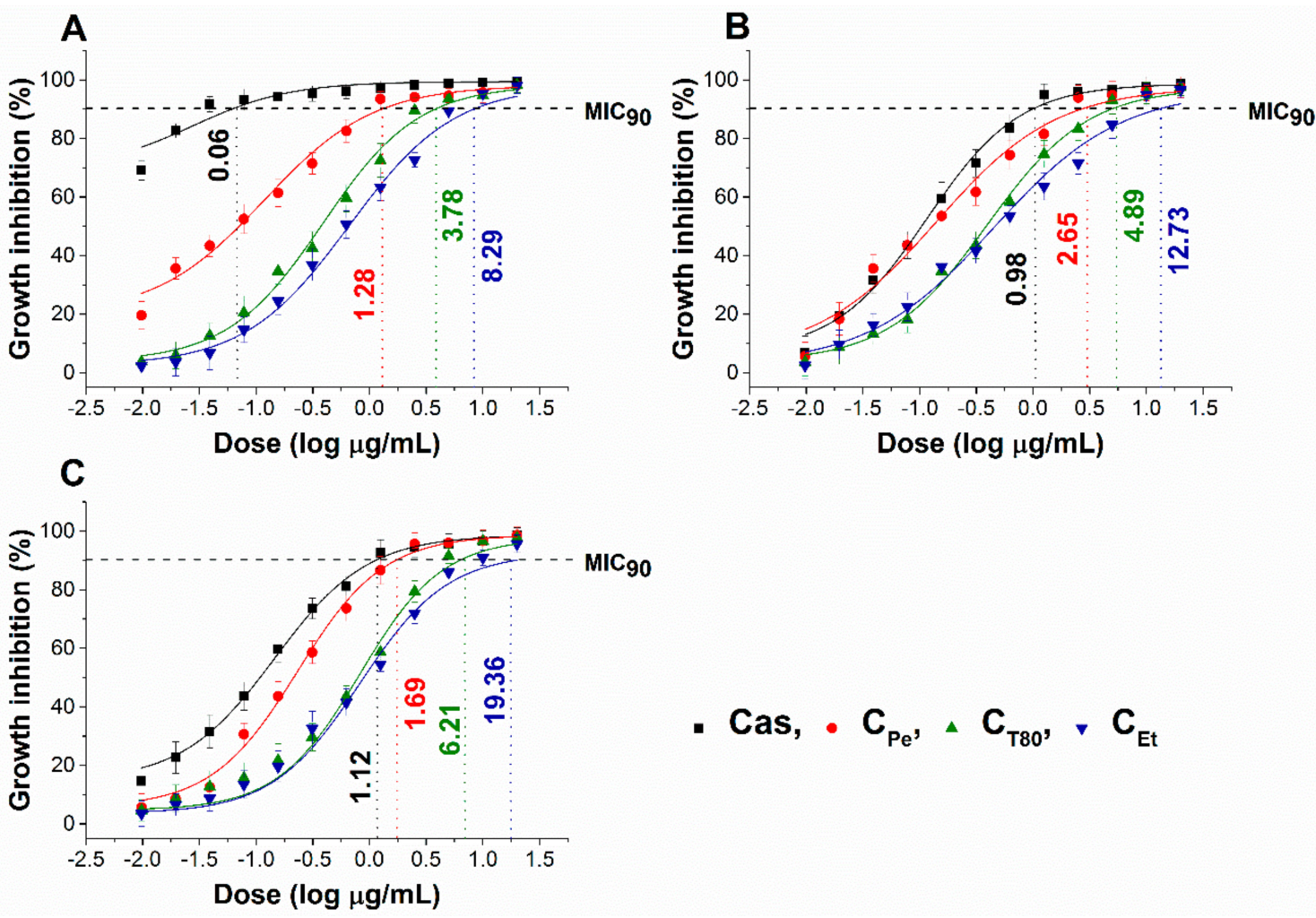

Figure 3. Minimum inhibitory concentration $\left(\mathrm{MIC}_{90}\right)$ of $\mathrm{C}_{\mathrm{Pe}}, \mathrm{CT}_{80}, \mathrm{C}_{\mathrm{Et}}$, and caspofungin $(\mathrm{Cas}, \mu \mathrm{g} / \mathrm{mL})$ on S. pombe (A), C. albicans (B), and C. tropicalis (C). 


\subsection{Minimum Effective Concentrations $\left(M E C_{10}\right)$ for Tested Bacteria and Fungi}

The minimum effective concentration ( $\left.\mathrm{MEC}_{10}\right)$ of $\mathrm{C}_{\mathrm{Pe}}, \mathrm{C}_{\mathrm{T} 80}$, and $\mathrm{C}_{\mathrm{Et}}$ on foodborne Gram-positive and Gram-negative bacteria as well as fungi have been determined. The dose-response curve shows a slow killing effect ( $\leq 10 \%$ of the population) of $\mathrm{C}_{\mathrm{Pe}}$ after $1 \mathrm{~h}$ of treatment at a two-fold higher concentration compared with $\mathrm{MIC}_{90}$ data. The $\mathrm{MEC}_{10}$ also highlights the effective killing effect of $\mathrm{C}_{\mathrm{Pe}}$ when compared to $\mathrm{C}_{\mathrm{T} 80}$ and $\mathrm{C}_{\mathrm{Et}}$ (Figures 4 and 5$)(P<0.01)$.

A

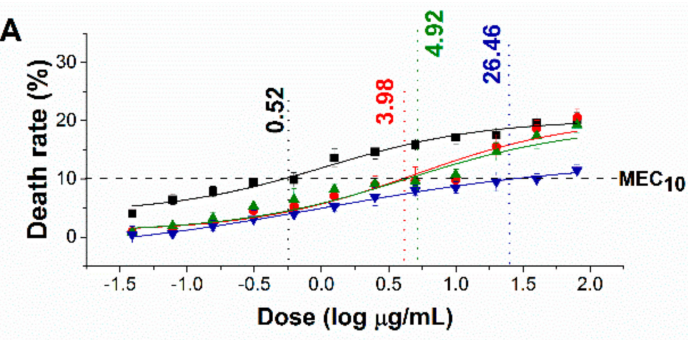

C

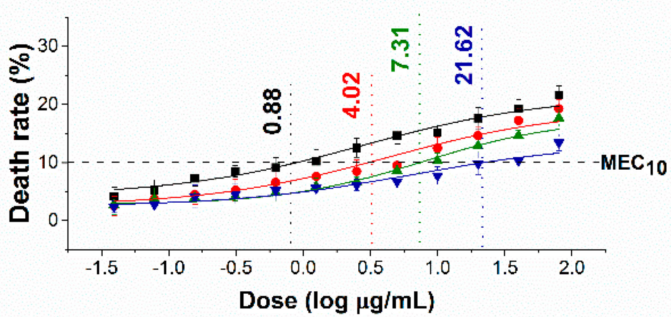

E

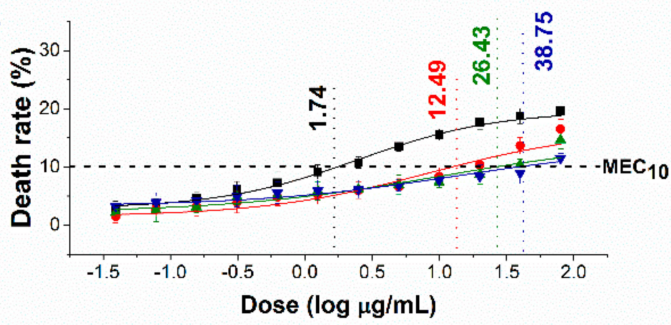

\section{B}

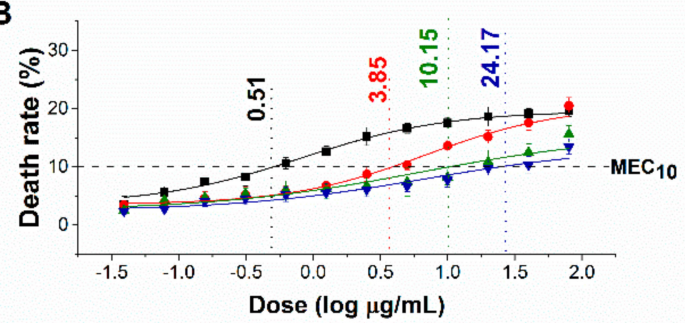

D

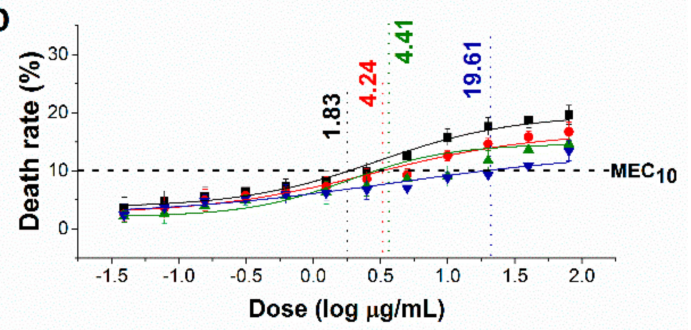

Figure 4. Minimum effective concentration ( $\left.\mathrm{MEC}_{10}\right)$ of $\mathrm{C}_{\mathrm{Pe}}, \mathrm{C}_{\mathrm{T} 80}, \mathrm{C}_{\mathrm{Et}}$, and Van $(\mu \mathrm{g} / \mathrm{mL})$ on E. coli $(\mathrm{A})$, S. aureus (B), B. subtilis (C), P. aeruginosa (D), and S. pyogenes (E).

\subsection{Effect on Microbial Oxidative Balance}

Reactive oxygen species (ROS) production and accumulation in the cells initiates oxidative stress, leading to cellular structural damage followed by induced apoptosis [6]. We have investigated the relationship between oxidative stress generation after $1 \mathrm{~h}$ of treatment and microbial killing activity. The results are demonstrated in Figures 6 and 7 for bacteria and fungi, respectively. Data expressed as $\%$ of the control are as follows: the ROS $(1085.86 \pm 126.36)$, peroxide $(1229.86 \pm 164.52)$ and superoxide $(1276.86 \pm 165.42)$ generation were the highest in case of $S$. aureus. The $\mathrm{C}_{\mathrm{Pe}}$ showed an effective increment of ROS, peroxide, and superoxide generation in both Gram-positive and -negative bacteria when compared to $C_{\mathrm{T} 80}$ and $\mathrm{C}_{\mathrm{Et}}(P<0.01)$. $\mathrm{C}_{\mathrm{Pe}}$ showed increased oxidative stress in both bacteria and fungi at least seven-fold higher than the negative control whereas the positive control (menadione) produced an eight- to nine-fold increase in $1 \mathrm{~h}$. The $\mathrm{C}_{\mathrm{Et}}$ has generated a two to four-fold increment in oxidative stress which is the lowest among all tested compounds.

\subsection{Time-Kill Kinetics Study}

The time-kill kinetics curve was performed to quantify living populations after a definite time interval under different sample $\mathrm{MEC}_{10}$ concentrations. A significant reduction (four log-fold) in the cell survivability has been observed in case of $C_{P e}$ when compared to $G c(P<0.01)$ (Figures 8 and 9 ). Fifty percent of cell death occurred by $\mathrm{C}_{\mathrm{Pe}}$ at 16 and $36 \mathrm{~h}$ in the case of bacteria and fungi, and was most 
effective in reducing living colonies in case of $C$. albicans $(1.73 \pm 0.15 \mathrm{CFU} / \mathrm{mL})$ after $48 \mathrm{~h}$ of treatment. At an average of a two-fold higher concentration, $C_{\mathrm{Et}}$ was able to show a killing effect compared to $C_{\mathrm{Pe}}$ $(P<0.01)$.
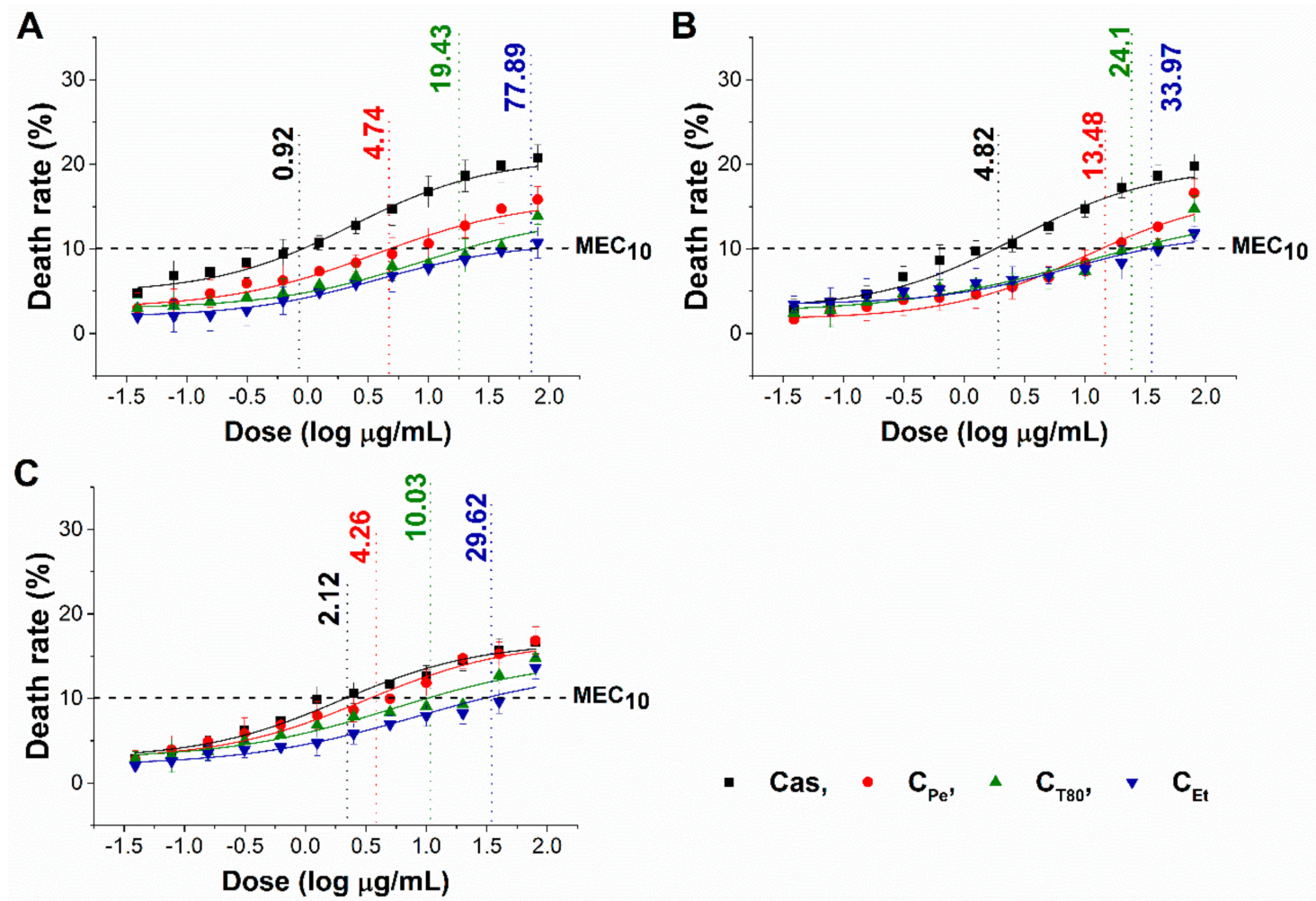

Figure 5. Minimum effective concentration $\left(\mathrm{MEC}_{10}\right)$ of $\mathrm{C}_{\mathrm{Pe}}, \mathrm{C}_{\mathrm{T} 80}, \mathrm{C}_{\mathrm{Et}}$, and $\mathrm{Cas}(\mu \mathrm{g} / \mathrm{mL})$ on S. pombe (A), C. albicans (B), and C. tropicalis (C).
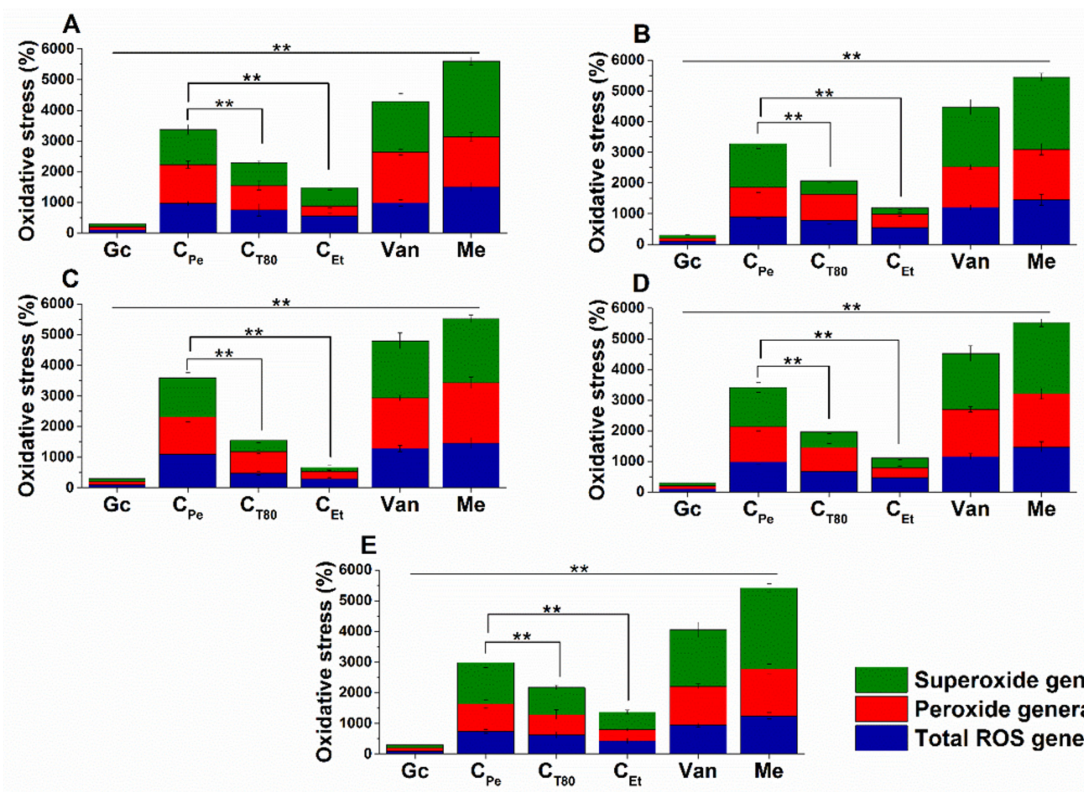

Superoxide generation Peroxide generation Total ROS generation

Figure 6. Percentage oxidative stress generation by $\mathrm{C}_{\mathrm{Pe}}, \mathrm{C}_{\mathrm{T} 80}, \mathrm{C}_{\mathrm{Et}}$, and Van on E. coli (A), S. aureus (B), B. subtilis (C), P. aeruginosa (D), and S. pyogenes (E). Six independent experiments, each with 3 replicates, compared with menadione (Me) and growth control $(\mathrm{Gc})$ as controls after $1 \mathrm{~h}$ of treatment $\left({ }^{* * P}<0.01\right)$. 

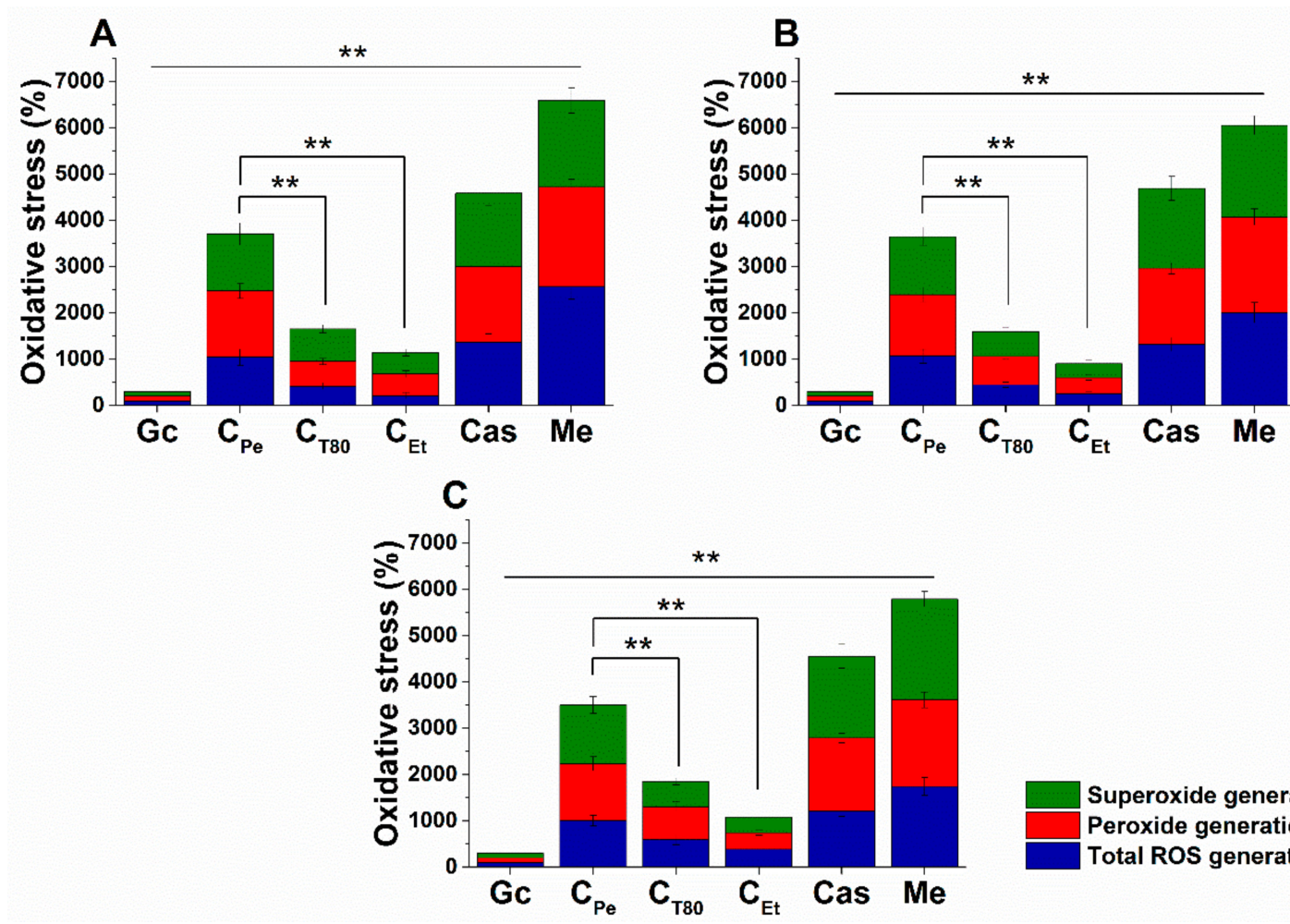

Superoxide generation

Peroxide generation

Total ROS generation

Figure 7. Percentage oxidative stress generation by $\mathrm{C}_{\mathrm{Pe}}, \mathrm{C}_{\mathrm{T} 80}, \mathrm{C}_{\mathrm{Et}}$, and Cas on S. pombe (A), C. albicans (B), and C. tropicalis (C). Six independent experiments, each with 3 replicates, compared with Me and Gc as positive and growth controls after $1 \mathrm{~h}$ of treatment $\left({ }^{* * P}<0.01\right)$.
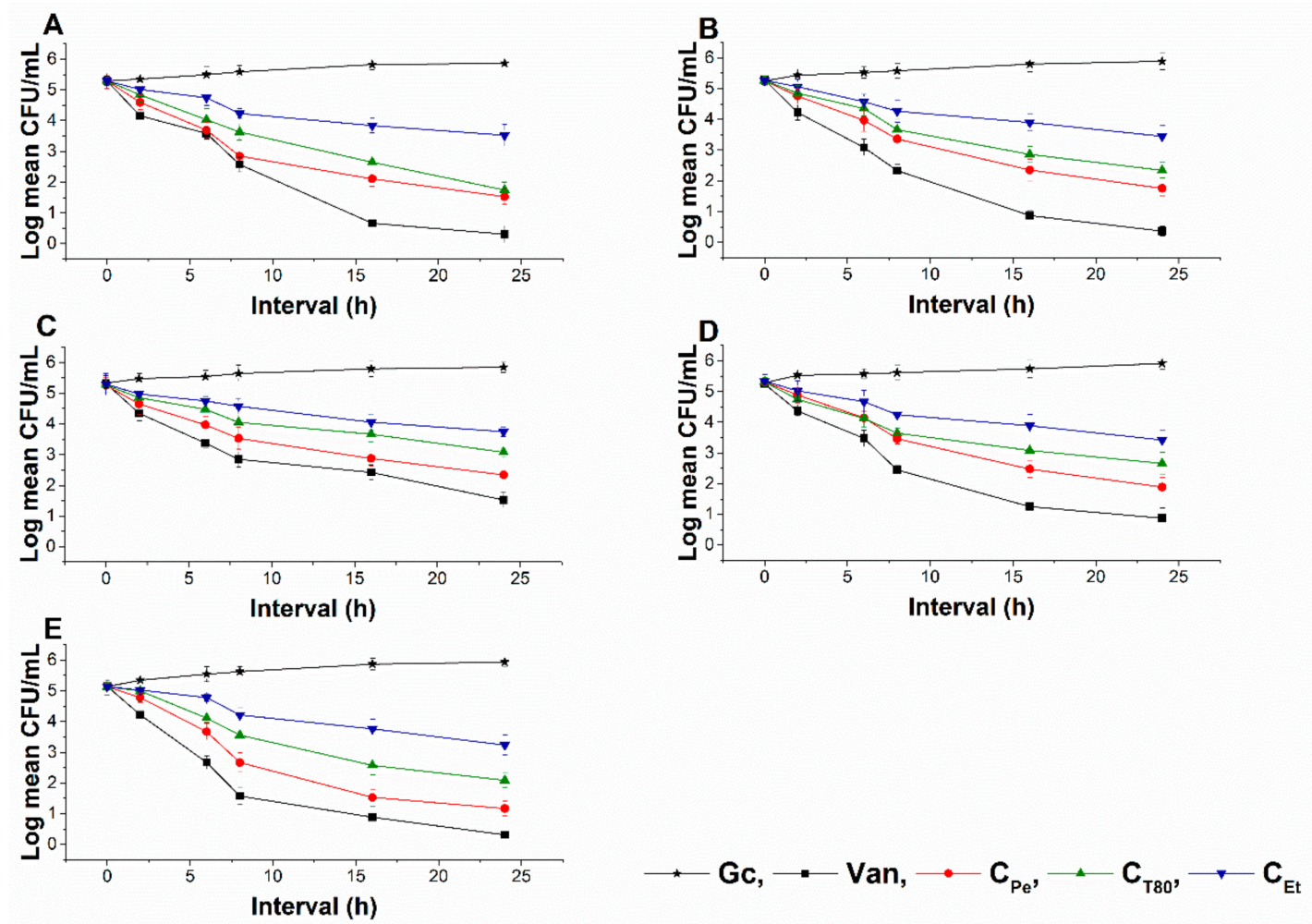

Figure 8. Colony-forming unit $(\mathrm{CFU} / \mathrm{mL})$ of $\mathrm{C}_{\mathrm{Pe}}, \mathrm{C}_{\mathrm{T} 80}$, and $\mathrm{C}_{\mathrm{Et}}$ on E. coli (A), S. aureus $(\mathbf{B})$, B. subtilis (C), P. aeruginosa (D), and S. pyogenes (E). Six independent experiments, each with 3 replicates, compared with Van and Gc as positive and growth controls. 

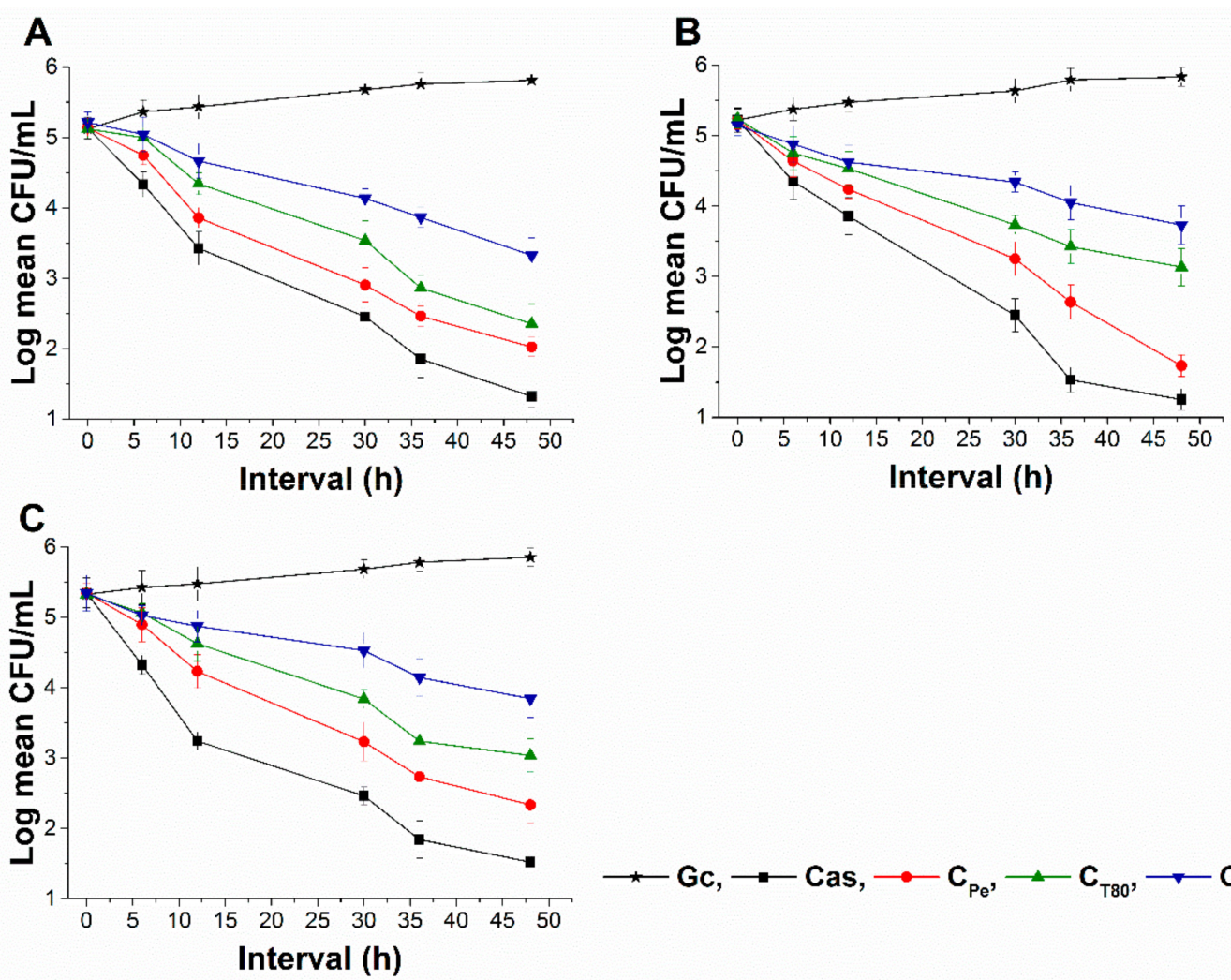

Figure 9. Colony-forming unit $(\mathrm{CFU} / \mathrm{mL})$ of $\mathrm{C}_{\mathrm{Pe}}, \mathrm{C}_{\mathrm{T} 80}$, and $\mathrm{C}_{\mathrm{Et}}$ on $\mathrm{S}$. pombe (A), C. albicans (B), and C. tropicalis (C). Six independent experiments, each with 3 replicates, compared with Cas and Gc as positive and growth controls.

\subsection{Live/dead Cell Viability Discrimination}

The effect of $\mathrm{C}_{\mathrm{Pe}}, \mathrm{C}_{\mathrm{T} 80}$, and $\mathrm{C}_{\mathrm{Et}}$ on the viability of selected bacteria and fungi were tested (Figures 10 and 11). $\mathrm{C}_{\mathrm{Pe}}$ decreases the viability of the tested bacteria and fungi with an average viability reduction to $42.36 \% \pm 3.74 \%$ and $49.62 \% \pm 5.25 \%$ of mean percentage viability compared to Gc after 16 and $36 \mathrm{~h}$ of treatments in bacteria and fungi respectively $(P<0.01)$, whereas $C_{\mathrm{T} 80}$ and $\mathrm{C}_{\mathrm{Et}}$ were less effective than $C_{\mathrm{Pe}}$ with mean percentage viabilities of $\geq 60 \%$ and $70 \%$, respectively.

\subsection{Interaction Study between Cell Model and Different Formulations of Chamomile EO}

The unilamellar liposomes (ULs), consisting of a single phospholipid, can be used as artificial cells or biological membrane model for studying the interactions between cells or cell membranes and drugs or biologically active components [24]. This study was conducted to determine the intracellular delivery ability of active components from chamomile EO for different formulations.

We have studied the interaction of ULs and different forms of chamomile EO for $24 \mathrm{~h}$ at $35^{\circ} \mathrm{C}$. After $1 \mathrm{~h}$ of interaction, 27.2\% of EO have penetrated the liposomes from Pickering nanoemulsion, while conventional emulsion and the ethanolic solution did not provide a measurable amount. The next sampling was after $2 \mathrm{~h}$, where Pickering emulsion has delivered $48.3 \%$ of EO, conventional emulsion $0.5 \%$, while the amount of EO delivered by the ethanolic solution was not measurable. Final sampling was after $24 \mathrm{~h}$, with $82.2 \%$ of chamomile EO found in the ULs when it was introduced in Pickering nanoemulsion form, and this value was $66.8 \%$ for conventional emulsion and $32.5 \%$ for the ethanolic solution (see Table 2). 

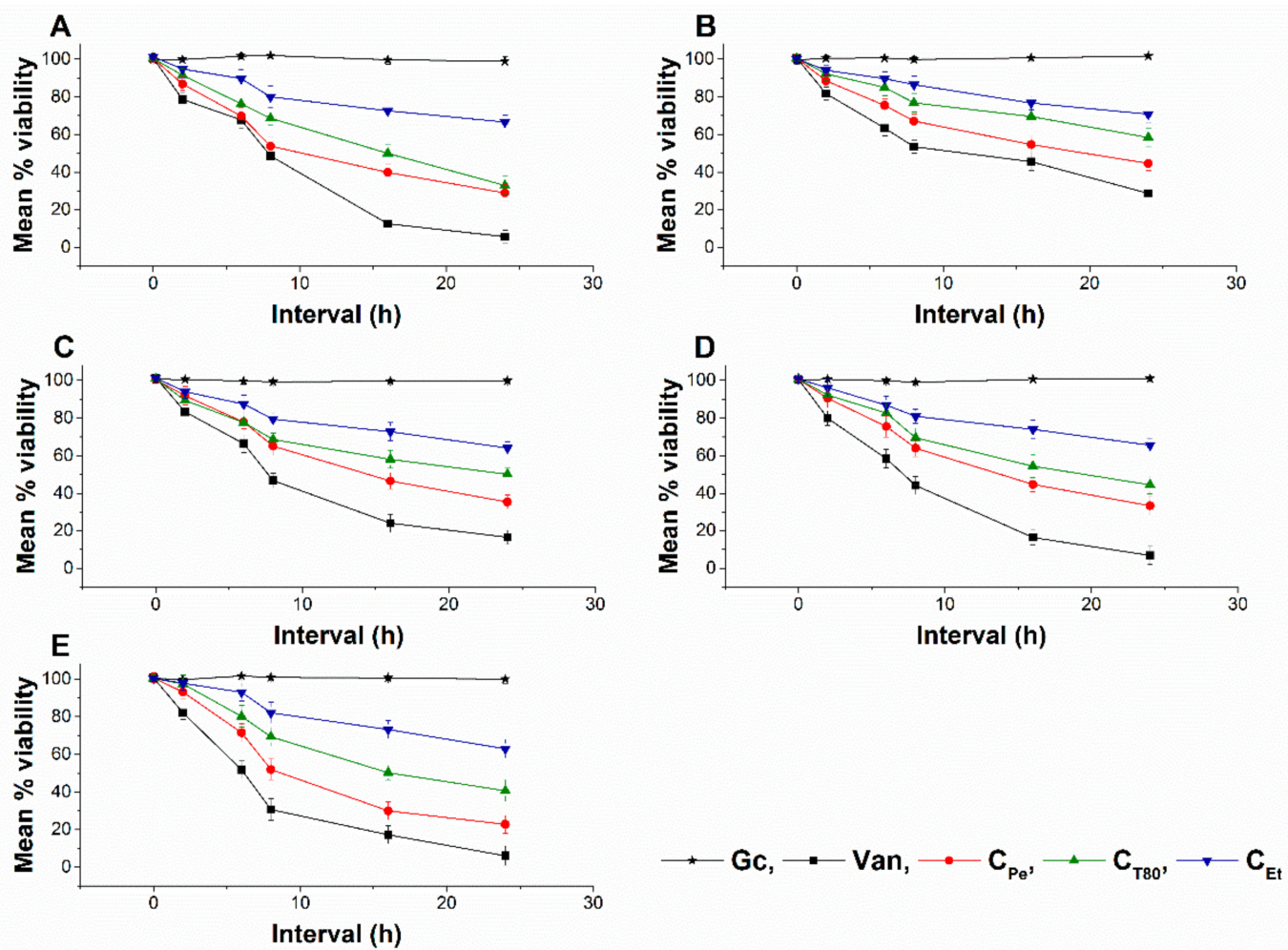

Figure 10. Mean percentage viability of $\mathrm{C}_{\mathrm{Pe}}, \mathrm{C}_{\mathrm{T} 80}$, and $\mathrm{C}_{\mathrm{Et}}$ on E. coli (A), S. aureus (B), B. subtilis (C), $P$. aeruginosa (D), and S. pyogenes (E). Six independent experiments, each with 3 replicates, compared with Van and Gc as positive and growth controls.

A
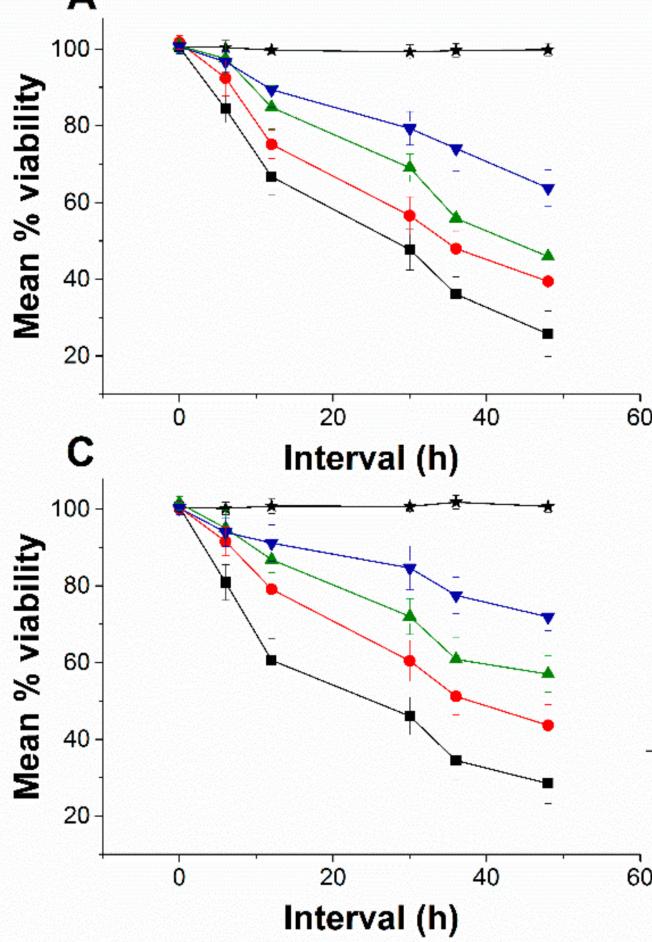

B

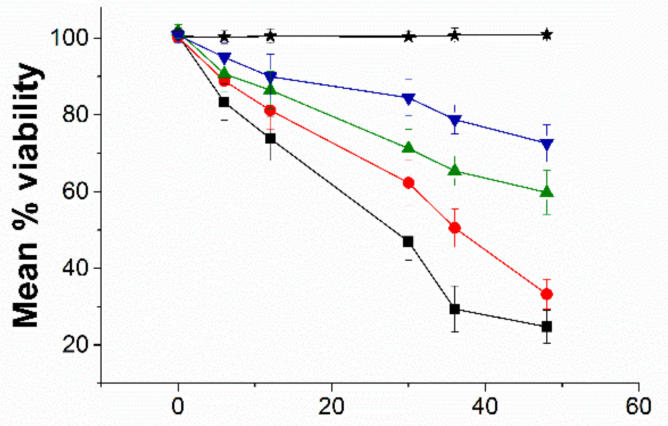

Interval (h)

Figure 11. Mean percentage viability of $\mathrm{C}_{\mathrm{Pe}}, \mathrm{C}_{\mathrm{T} 80}$, and $\mathrm{C}_{\mathrm{Et}}$ on $S$. pombe (A), C. albicans (B) and C. tropicalis $(\mathbf{C})$. Six independent experiments, each with 3 replicates, compared with Cas and Gc as positive and growth controls. 
Table 2. Results of the interaction study between unilamellar liposomes (Uls) and different formulations of chamomile EO. PA means the amount in the percentage of penetrated chamomile EO. Standard deviations were calculated from 3 independent experiments.

\begin{tabular}{cccc}
\hline Formulation & $\mathbf{P A}_{\mathbf{1 h}}$ & $\mathbf{P A}_{\mathbf{2 h}}$ & $\mathbf{P A}_{\mathbf{2 4 h}}$ \\
\hline $\mathrm{C}_{\mathrm{Pe}}$ & $27.2 \pm 3.7$ & $48.3 \pm 5.1$ & $82.2 \pm 4.9$ \\
$\mathrm{C}_{\mathrm{T} 80}$ & - & $0.5 \pm 0.1$ & $66.8 \pm 3.6$ \\
$\mathrm{C}_{\mathrm{Et}}$ & - & - & $35.5 \pm 1.0$ \\
\hline
\end{tabular}

\section{Discussion}

The effect of three different formulations on antimicrobial activity of chamomile essential oil has been examined. We have successfully prepared stable Pickering nanoemulsion using silica nanoparticles with appropriate lipophilicity. The emulsion was stable for three months. The effectiveness of Pickering emulsion was compared with conventional emulsion and ethanolic solution.

Based on our antimicrobial activity analyses, $\mathrm{C}_{\mathrm{Pe}}$ shows higher growth inhibitory action and consequently lower MICs compared to $\mathrm{C}_{\mathrm{T} 80}$ and $\mathrm{C}_{\mathrm{Et}}$. Many researchers have studied the antimicrobial activity of chamomile oil $[3,7,13,23,25]$, however, the mechanism of action at subinhibitory concentrations has not previously been studied. Our data suggest an effective killing activity of $\mathrm{C}_{\mathrm{Pe}}$ on selected bacteria and fungi. It is believed that EOs act against cell cytoplasmic membrane and induce stress in microorganisms [26-29]. To visualize the effects of $\mathrm{C}_{\mathrm{Pe}}, \mathrm{C}_{\mathrm{T} 80}$, and $\mathrm{C}_{\mathrm{Et}}$, we introduced different staining methods to understand their mechanism. $\mathrm{C}_{\mathrm{Pe}}$ was able to generate higher oxidative stress compared to the conventional emulsion and ethanolic solution followed by metabolic interference and cell wall disruption and finally caused cell death at subinhibitory concentration [21,30-33].

The results obtained in the model experiment show that $C_{\mathrm{Pe}}$ is the most effective form for the intracellular delivery of chamomile EO. Based on these results it can be established that the different antibacterial and antifungal effects may be caused by the difference of adsorption properties of EO forms to the microbial cells. The mechanism of delivery has not been revealed in this study, but evidence for the adsorption of Pickering emulsion droplets on the cell membrane has been previously reported [18]. Assuming the adsorption of $\mathrm{C}_{\mathrm{Pe}}$ droplets on the cell membrane of investigated microbes, intracellular delivery of active components from EO is feasible in two ways. Passive diffusion is caused by the higher local concentration gradient of $\mathrm{EO}$ on the cell membrane, or fusion of $\mathrm{C}_{\mathrm{Pe}}$ droplets with microbial cells. Overall, our observations demonstrate that $C_{\mathrm{Pe}}$ facilitates chamomile oil to permeate cells, inducing oxidative stress and disrupting the membrane integrity because of higher adsorption efficacy of chamomile EO. SNP acts as a stabilizer, inhibiting the easy escape of EOs from the emulsion system compared to the conventional emulsion and free oils.

\section{Materials and Methods}

\subsection{Synthesis, Surface Modification, and Characterization of Stöber Silica Nanoparticles}

We have performed the synthesis of $20 \mathrm{~nm}$ hydrophilic silica nanoparticles with the previously reported modified Stöber method [9]. Briefly, a solution of tetraethoxysilane (TEOS) and ultrapure water in ethanol was prepared by using tetraethoxysilane, (Thermo Fisher $\mathrm{GmbH}$, Kandel, Germany, pur. 98\%); absolute ethanol AnalaR Normapur $\geq 99.8 \%$ purity (VWR Chemicals, Debrecen, Hungary) and water (membraPure Astacus Analytical with UV, VWR Chemicals, Debrecen, Hungary). The solution was stirred for $20 \mathrm{~min}$ and sonicated for another $20 \mathrm{~min}$ (Bandelin Sonorex RK 52H, BANDELIN electronic $\mathrm{GmbH} \& \mathrm{Co}$. KG, Berlin, Germany). An appropriate amount of $\mathrm{NH}_{3}$ solution $(28 \%(w / w)$ ammonium solution, VWR Chemicals, Debrecen, Hungary) was added to the reaction mixture and was stirred at $1000 \mathrm{rpm}$ for $24 \mathrm{~h}$ at room temperature $\left(25^{\circ} \mathrm{C}\right)$. The molar ratio of components was water/ethanol/TEOS/ $\mathrm{NH}_{3}=100: 300: 5.2: 1$. The surface of hydrophilic silica nanoparticles was modified with propyltriethoxysilane (PTES Alfa Aesar, Haverhill, MA, USA, pur. 99\%) in a post-synthesis modification reaction [32]. The ethanolic solution of the modifying agent was added to the freshly 
prepared hydrophilic silica nanoparticle suspensions; the mixtures were stirred for $6 \mathrm{~h}$ with $1000 \mathrm{rpm}$ at room temperature. Before further use of the SNPs, the ammonium hydroxide and ethanol were always removed from the reaction mixture by distillation (Heidolph Laborota 4000, Heidolph Instruments $\mathrm{GmbH} \& \mathrm{CO}$. KG, Germany). The water content was supplemented three times. The concentration of silica nanoparticle water-based suspension was finally adjusted to $1 \mathrm{mg} / \mathrm{cm}^{3}$.

The size distribution and zeta potential of silica nanoparticles were determined by dynamic light scattering (DLS) using Malvern Zetasizer NanoS and NanoZ instruments (Malvern Instruments-Malvern Panalytical, Worcester, UK). The morphology and size distribution were also examined with transmission electron microscopy (TEM), (JEOL JEM-1200 EX II and JEM-1400, JEOL Ltd., Tokyo, Japan). The samples were dropped onto 200 mesh copper grids coated with carbon film (EMR Carbon support grids, Micro to Nano Ltd, Haarlem, The Netherlands) from diluted suspensions.

\subsection{Preparation and Characterization of Pickering Nanoemulsion}

As stabilizing agents, surface-modified silica nanoparticles or Tween 80 surfactant (Polysorbate80, Acros Organics, New Jersey, NJ, USA) were used. The concentration of stabilizing agents and chamomile essential oil (bluish Matricaria chamomilla oil, Aromax Ltd., Budapest, Hungary) was kept constant for all experiments, the values were $1 \mathrm{mg} / \mathrm{mL}$ and $100 \mu \mathrm{g} / \mathrm{mL}$, respectively. The first step of the emulsification process was sonication for 2 minutes (Bandelin Sonorex RK 52H, BANDELINelectronic GmbH \& Co. KG, Germany), then emulsification using UltraTurrax (IKA Werke T-25 basic, IKA®-Werke GmbH \& Co. KG, Germany) for $5 \mathrm{~min}$ at 21,000 rpm. To compare the different formulations, an ethanolic solution was also prepared; chamomile essential oil was added to absolute ethanol at $100 \mu \mathrm{g} / \mathrm{mL}$ concentration, and the solution was sonicated for $5 \mathrm{~min}$.

The stability of Pickering emulsion was studied from periodical droplet size determination using DLS measurements (Malvern Zetasizer Nano S, Malvern Panalytical Ltd, Worcester, UK).

\subsection{Materials for Biological Experiments}

In these experiments, the sterile 96-well microtiter plates were from Greiner Bio-One (Kremsmunster, Austria), potassium phosphate monobasic, glucose, adenine, 96\% ethanol (Et), peptone, yeast extract, agar-agar, and Mueller Hinton agar were from Reanal Labor (Budapest, Hungary), modified RPMI 1640 (contains 3.4\% MOPS, 1.8\% glucose, and 0.002\% adenine), SYBR green I 10,000×, propidium iodide, dihydrorhodamine 123 (DHR 123), 2' , $^{\prime}$-dichlorofluorescin diacetate (DCFDA), dihydroethidine (DHE) and menadione (Me) were from Sigma-Aldrich Chemie GmbH (Steinheim, Germany), disodium phosphate and dimethyl sulfoxide (DMSO) were from Chemolab Ltd. (Budapest, Hungary), sodium chloride from VWR Chemicals (Debrecen, Hungary), potassium chloride was from Scharlau Chemie S.A (Barcelona, Spain), 3-(N-morpholino) propanesulfonic acid (MOPS) was from Serva Electrophoresis GmbH (Heidelberg, Germany), caspofungin (Cas) from Merck Sharp \& Dohme Ltd (Hertfordshire, UK), vancomycin (Van) from Fresenius Kabi Ltd. (Budapest, Hungary), $0.22 \mu \mathrm{m}$ vacuum filters from Millipore (Molsheim, France) and the cell spreader was from Sarstedt AG \& Co. KG (Numbrecht, Germany). All other chemicals used in the study were of analytical or spectroscopic grade. For fungi, we used an in-house nutrient agar medium [34] while phosphate-buffered saline (PBS, pH 7.4) was from Life Technologies Ltd. (Budapest, Hungary). Highly purified water $(<1.0 \mu S)$ was applied throughout the studies.

\subsection{Determination of Minimum Inhibitory Concentration $\left(\mathrm{MIC}_{90}\right)$}

\subsubsection{Microorganisms}

Escherichia coli (E. coli) PMC 201, Pseudomonas aeruginosa (P. aeruginosa) PMC 103, Bacillus subtilis (B. subtilis) SZMC 0209, Staphylococcus aureus (S. aureus) ATCC 29213, Streptococcus pyogenes (S. pyogenes) SZMC 0119, Schizosaccharomyces pombe (S. pombe) ATCC 38366, Candida albicans (C. albicans) ATCC 1001, and Candida tropicalis (C. tropicalis) SZMC 1368 were obtained from Szeged Microbial Collection, 
Department of Microbiology, University of Szeged, Hungary (SZMC) and Department of General and Environmental Microbiology, Institute of Biology, University of Pecs, Hungary (PMC).

\subsubsection{Antimicrobial Activity Tests}

The antibacterial activity of the tested drugs was separately evaluated on E. coli, P. aeruginosa, $B$. subtilis, S. aureus, and S. pyogenes according to our previously published protocol [35]. In brief, bacterial populations of $\sim 10^{5} \mathrm{CFU} / \mathrm{mL}$ were inoculated into RPMI media and incubated for $16 \mathrm{~h}$ at $35 \pm 2{ }^{\circ} \mathrm{C}$ with test compounds $\left(\mathrm{C}_{\mathrm{Pe}}, \mathrm{C}_{\mathrm{T} 80}, \mathrm{C}_{\mathrm{Et}}\right.$, and Van) over a wide concentration range $(0.3-0.01 \mu \mathrm{g} / \mathrm{mL})$. The absorbance was measured by a Thermo Scientific Multiskan EX 355 plate reader (InterLabsystems, Budapest, Hungary) at $600 \mathrm{~nm}$.

The antifungal activity against S. pombe, C. albicans, and C. tropicalis species were also carried out according to our previously published method [35]. Briefly, $\sim 10^{3}$ cells $/ \mathrm{mL}$ were incubated for $48 \mathrm{~h}$ at $30 \pm 2{ }^{\circ} \mathrm{C}$ with test compounds $\left(\mathrm{C}_{\mathrm{Pe}}, \mathrm{C}_{\mathrm{T} 80}, \mathrm{C}_{\mathrm{Et}}\right.$ and Cas) at wide concentration range $(20-0.01 \mu \mathrm{g} / \mathrm{mL})$ in modified RPMI media. The absorbance was measured by a Thermo Scientific Multiskan EX 355 plate reader (InterLabsystems, Budapest, Hungary) at $595 \mathrm{~nm}$. Absorbance values were converted to percentages compared to growth control $(\sim 100 \%)$ and data were fitted by nonlinear dose-response curve method to calculate the dose producing $\geq 90 \%$ growth inhibition $\left(\mathrm{MIC}_{90}\right)$. All the measurements were performed by applying three technical replicates in six independent experiments. Van and Cas were used as a standard antibacterial and antifungal drug, respectively, throughout the experiments.

\subsection{Determination of Minimum Effective Concentration $\left(M E C_{10}\right)$}

The assay has been designed to determine the killing effects of the test compounds for a certain period of time. In brief, a wide concentration range $(0.03-80 \mu \mathrm{g} / \mathrm{mL})$ of the test samples were used to treat $\sim 10^{6}$ cells $/ \mathrm{mL}$ for one hour. One milliliter of treated and untreated samples were taken and were diluted $10^{5}$ times followed by spreading $50 \mu \mathrm{L}$ samples onto $20 \mathrm{~mL}$ nutrient agar media and incubated for $24 \mathrm{~h}$ at $35^{\circ} \mathrm{C}$ (bacteria) and $30^{\circ} \mathrm{C}$ (fungi) for colony-forming unit $(\mathrm{CFU} / \mathrm{mL}$ ) quantification. The data were compared with growth control and positive control (Van for bacteria and Cas for fungi) for percentage mortality ( $10 \%$ death) determination. It is noteworthy that in the $\mathrm{MEC}_{10}$ experiments, the inoculated microbial cell number was $10^{3}$ times higher than was used in the $\mathrm{MIC}_{90}$ determinations $\left(10^{6}\right.$ vs. $10^{3}$ ). However, in both cases, the same formula was used (see Section 4.7). All the measurements were performed by applying three technical replicates in six independent experiments.

\subsection{Determination of Microbial Oxidative Generation and Killing Activity}

\subsubsection{Quantification of Total ROS Generation}

Total ROS generation was assayed according to previously published protocols $[27,28,34,36]$. Briefly, $\sim 10^{6}$ cells $/ \mathrm{mL}$ were collected and centrifuged at $1500 \mathrm{~g}$ for $5 \mathrm{~min}$ and were suspended in PBS. The cells were stained with a $20 \mathrm{mM}$ stock solution of DCFDA in PBS (pH 7.4) to achieve an end concentration of $25 \mu \mathrm{M}$, and were incubated at $35{ }^{\circ} \mathrm{C}$ (for bacteria) and $30{ }^{\circ} \mathrm{C}$ (for fungi) for $30 \mathrm{~min}$ in the dark with mild shaking. The cells were centrifuged (Hettich Rotina 420R, Auro-Science Consulting Ltd., Budapest, Hungary) and suspended in RPMI media. The cells were treated with $\mathrm{C}_{\mathrm{Pe}}, \mathrm{C}_{\mathrm{T} 80}, \mathrm{C}_{\mathrm{Et}}$, Van (bacteria), and Cas (fungi) at their respective $\mathrm{MEC}_{10}$ concentrations for one hour. The fluorescence signals were recorded at $\mathrm{Ex} / \mathrm{Em}=485 / 535 \mathrm{~nm}$ wavelengths by a Hitachi F-7000 fluorescence spectrophotometer/plate reader (Auro-Science Consulting Ltd., Budapest, Hungary). The percentage increase in oxidative balance was measured by comparing the signals to those of the growth controls $(\mathrm{Gc})$. Six independent experiments were done with three technical replicates for each treatment. 


\subsubsection{Detection of Peroxide $\left(\mathrm{O}_{2}{ }^{2-}\right)$ and Superoxide Anion $\left(\mathrm{O}_{2}{ }^{\bullet-}\right)$ Generation}

The previously described protocol was adapted for peroxide [36,37] and superoxide anion radicals [34,38] with modifications. A positive control, $\mathrm{Me}\left(0.5 \mathrm{mmol} / \mathrm{L}\right.$ as end concentration), $\mathrm{C}_{\mathrm{Pe}}, \mathrm{C}_{\mathrm{T} 80}$, $\mathrm{C}_{\mathrm{Et}}$, Van (bacteria), and Cas (fungi) at their respective $\mathrm{MEC}_{10}$ concentrations were used to treat the cell suspensions $\left(\sim 10^{6}\right.$ cells $\left./ \mathrm{mL}\right)$ for an hour at $35^{\circ} \mathrm{C}$ (bacteria) and $30^{\circ} \mathrm{C}$ (fungi) in RPMI media. Thereafter, the cells were centrifuged at $1500 \mathrm{~g}$ for $5 \mathrm{~min}$ at room temperature followed by resuspension of pellets in PBS of the same volume. DHR $123(10 \mu \mathrm{mol} / \mathrm{L}$, end concentration) and DHE (15 $\mu \mathrm{mol} / \mathrm{L}$, end concentration) were added separately to the cell samples for peroxide and superoxide determination. The stained cells were further incubated at $35{ }^{\circ} \mathrm{C}$ (bacteria) and $30{ }^{\circ} \mathrm{C}$ (fungi) in the dark with mild shaking. The samples were centrifuged and resuspended in PBS followed by the distribution of the samples into the wells of 96-well microplates. The fluorescence was measured at excitation/emission wavelengths of 500/536 nm for peroxides and 473/521 nm for superoxide detection by a Hitachi F-7000 fluorescence spectrophotometer/plate reader (Auro-Science Consulting Ltd., Budapest, Hungary). The percentage increase in oxidative stress was measured by comparing the signals to those of the growth controls (Gc). Six independent experiments were done with three technical replicates for each treatment.

\subsubsection{Time-Kill Kinetics Assay}

We followed a protocol previously published by T. Appiah et. al., with modifications [39]. In brief, $\mathrm{C}_{\mathrm{Pe}}, \mathrm{C}_{\mathrm{T} 80}, \mathrm{C}_{\mathrm{Et}}$, Van (bacteria), and Cas (fungi) at their respective $\mathrm{MEC}_{10}$ concentrations were used to treat the microbial population of $\sim 10^{6} \mathrm{CFU} / \mathrm{mL}$ and were incubated at $35{ }^{\circ} \mathrm{C}$ (bacteria) and $30{ }^{\circ} \mathrm{C}$ (fungi). One milliliter of the treated and untreated samples was pipetted at time intervals of 0 , $2,6,8,16$, and $24 \mathrm{~h}$ for bacteria, and $0,6,12,30,36$, and $48 \mathrm{~h}$ for fungi, and were diluted $10^{5}$ times followed by spreading $50 \mu \mathrm{L}$ onto $20 \mathrm{~mL}$ nutrient agar media using a cell spreader and incubated at 35 ${ }^{\circ} \mathrm{C}$ (bacteria) and $30{ }^{\circ} \mathrm{C}$ (fungi) for $24 \mathrm{~h}$. Van and Cas were used as reference controls for bacteria and fungi. Control without treatment was considered as growth control (Gc). The colony-forming unit $(\mathrm{CFU} / \mathrm{mL})$ of the microorganisms were determined, performed in triplicate and was plotted against time (h). Six independent experiments were done with three technical replicates for each treatment.

\subsubsection{Live/dead Discrimination of Microbial Cells}

For live/dead cell discrimination, we followed the protocol published previously [35]. In brief, the cell population of $\sim 10^{6}$ cells/mL were treated with $\mathrm{C}_{\mathrm{Pe}}, \mathrm{C}_{\mathrm{T} 80}, \mathrm{C}_{\mathrm{Et}}$, Van (bacteria), and Cas (fungi) at their respective $\mathrm{MEC}_{10}$ concentrations and were incubated at $35^{\circ} \mathrm{C}$ (bacteria) and $30{ }^{\circ} \mathrm{C}$ (fungi). Treated and untreated samples were pipetted at time intervals of $0,2,6,8,16$, and $24 \mathrm{~h}$ for bacteria, and $0,6,12,30$, 36 and $48 \mathrm{~h}$ for fungi followed by centrifugation at $1000 \mathrm{~g}$ for $5 \mathrm{~min}$, washed, and resuspended in PBS (100 $\mu \mathrm{L} /$ well). One hundred microliters of freshly prepared working dye solution in PBS (using $20 \mu \mathrm{L}$ SYBR green I and $4 \mu \mathrm{L}$ propidium iodide diluted solutions as described earlier) were added to the samples. The plate was incubated at room temperature for $15 \mathrm{~min}$ in the dark with mild shaking. A Hitachi F-7000 fluorescence spectrophotometer/plate reader (Auro-Science, Consulting Ltd., Budapest, Hungary) was used to measure the fluorescence intensities of SYBR green I (excitation/emission wavelengths: 490/525 nm) and propidium iodide (excitation/emission wavelengths: 530/620 nm), respectively. A green to red fluorescence ratio for each sample and for each dose was achieved and the $\%$ of dead cells with the response to the applied dose was plotted against the applied test compound doses using a previously published formula [35]. All treatments were done in triplicates and six independent experiments were performed.

\subsection{Statistical Analysis of Microbiological Experiments}

All data were given as mean \pm SD. Graphs and statistical analyses were conducted using OriginPro 2016 (OriginLab Corp., Northampton, MA, USA). All experiments were performed independently six 
times and data were analyzed by one-way ANOVA test. $P<0.01$ was considered statistically significant. The growth inhibition concentration $\left(\mathrm{MIC}_{90}\right)$ and minimum effective concentration $\left(\mathrm{MEC}_{10}\right)$ were calculated using a nonlinear dose-response sigmoidal curve function as follows:

$$
y=A_{1}+\frac{A_{2}-A_{1}}{1+10^{\left(\log _{x} 0-x\right) p}}
$$

where $\mathrm{A} 1, \mathrm{~A} 2, \mathrm{LOG}_{\mathrm{x}} \mathrm{O}$ and $\mathrm{p}$ as the bottom asymptote, top asymptote, center, and hill slope of the curve have been considered.

\subsection{Interaction Study between the Cell Model (Unilamellar Liposomes) and Different Formulations of Chamomile EO}

Unilamellar liposomes (ULs) have been prepared from phosphatidylcholine (Phospolipon 90G, Phospholipid GmbH, Berlin, Germany) by the modified method described before by Alexander Moscho et al. [40]. Phosphatidylcholine was dissolved in chloroform ( $\geq 98 \%$ stabilized, VWR Chemicals, Debrecen, Hungary) in $0.1 \mathrm{M}$ concentration, and $150 \mu \mathrm{L}$ of this solution was diluted in a mixture of $6 \mathrm{~mL}$ chloroform and $1 \mathrm{~mL}$ of methanol. This solution was added dropwise to $40 \mathrm{~mL}$ of PBS buffer while stirring on a magnetic stirrer at $600 \mathrm{rpm}$ (VELP Scientifica Microstirrer, Magnetic Stirrer, Usmate Velate $\mathrm{MB}$, Italy). The solvents were removed on a rotational evaporator at $40{ }^{\circ} \mathrm{C}$ (Heidolph Laborota 4000, Heidolph Instruments GmbH \& CO. KG, Germany). The resulting suspension volume was set to $25 \mathrm{~mL}$ with PBS buffer and stored in the refrigerator at $8^{\circ} \mathrm{C}$ until further use. A $5 \mathrm{~mL}$ suspension of ULs was mixed with $3 \mathrm{~mL}$ Pickering nanoemulsion, conventional emulsion, or ethanolic solution, and the chamomile EO concentration was $100 \mu \mathrm{g} / \mathrm{mL}$ for the different formulations. The mixture was stirred at $600 \mathrm{rpm}$ for $24 \mathrm{~h}$ at $35^{\circ} \mathrm{C}$, and $1 \mathrm{~mL}$ aliquots were taken after 1,2 , and $24 \mathrm{~h}$. The samples were centrifuged at $3000 \mathrm{rpm}$ and $20^{\circ} \mathrm{C}$ for $5 \mathrm{~min}$, and the ULs were collected and dissolved in absolute ethanol. The chamomile-EO content of samples was determined with UV/VIS Spectroscopy at $290 \mathrm{~nm}$ (Jasco V-550 UV/VIS Spectrophotometer; Jasco Inc., Easton, MD, USA). For UV/VIS measurements we have prepared samples without chamomile-EOs, i.e., ULs with SNP suspension, Tween 80 solution, or ethanol were also mixed and centrifuged and were used as blanks.

\subsection{GC-MS Analysis of Chamomile EO}

Gas chromatography and mass spectrometry (GC-MS) analyses were carried out on an Agilent Technologies (Palo Alto, CA, USA) gas chromatograph model 7890A with 5975C mass detector. Operating conditions were as follows: column HP-5MS (5\% phenylmethyl polysiloxane), $30 \mathrm{~m} \times$ $0.25 \mathrm{~mm}$ i.d., $0.25 \mu \mathrm{m}$ coating thickness. Helium was used as the carrier gas at $1 \mathrm{~mL} / \mathrm{min}$, injector temperature was $250^{\circ} \mathrm{C}$. HP-5MS column temperature was programmed at $70^{\circ} \mathrm{C}$ isothermal for $2 \mathrm{~min}$, and then increased to $200{ }^{\circ} \mathrm{C}$ at a rate of $3{ }^{\circ} \mathrm{C} / \mathrm{min}$ and held isothermal for $18 \mathrm{~min}$. The split ratio was 1:50, ionization voltage $70 \mathrm{eV}$; ion source temperature $230{ }^{\circ} \mathrm{C}$; mass scan range: $45-450$ mass units. The percentage composition was calculated from the GC peak areas using the normalization method (without correction factors). The component percentages were calculated as mean values from duplicate GC-MS analyses of the oil sample. The results of GC-MS analysis can be seen in Supplementary Materials.

Supplementary Materials: The followings are available online: Composition of chamomile essential oil analyzed by GC-MS method. Results can be seen in Supplementary Table S1 and Figure S1.

Author Contributions: Conceptualization T.K., and A.S.; methodology S.D., B.H., T.K. and A.S.; software, S.D.; formal analysis, S.D. and B.H.; investigation, S.D. and B.H.; GC analysis S.Š. and S.J. resources, A.S.; data curation, S.D., B.H.; writing—original draft preparation, S.D. and B.H.; writing-review and editing, T.K. and A.S.; visualization, S.D. and B.H.; supervision, T.K. and A.S.; funding acquisition A.S. and T.K.

Funding: This work was supported by EFOP 3.6.1-16-2016-00004 project (Comprehensive Development for Implementing Smart Specialization Strategies at the University of Pécs), University of Pécs, Medical School, KA-2018-17 and NKFI-EPR K/115394/2015 grants. 
Conflicts of Interest: The authors declare no conflict of interest.

\section{References}

1. Manion, C.R.; Widder, R.M. Essentials of essential oils. Am. J. Health-Syst. Pharm. 2017, 74, e153-e162. [CrossRef]

2. Omonijo, F.A.; Ni, L.; Gong, J.; Wang, Q.; Lahaye, L.; Yang, C. Essential oils as alternatives to antibiotics in swine production. Anim. Nutr. 2018, 4, 126-136. [CrossRef]

3. McKay, D.L.; Blumberg, J.B. A Review of the bioactivity and potential health benefits of chamomile tea (Matricaria recutita L). Phytother. Res. 2006, 20, 519-530. [CrossRef]

4. Lis-Balchin, M. Aromatherapy Science: A Guide for Healthcare Professionals; Pharmaceutical Press: London, UK, 2006; ISBN 978-0-85369-578-3.

5. Pfaller, M.A.; Sheehan, D.J.; Rex, J.H. Determination of Fungicidal Activities against Yeasts and Molds: Lessons Learned from Bactericidal Testing and the Need for Standardization. Clin. Microbiol. Rev. 2004, 17, 268-280. [CrossRef]

6. Donsì, F.; Ferrari, G. Essential oil nanoemulsions as antimicrobial agents in food. J. Biotechnol. 2016, 233, 106-120. [CrossRef] [PubMed]

7. Singh, O.; Khanam, Z.; Misra, N.; Srivastava, M. Chamomile (Matricaria chamomilla L.): An overview. Pharmacogn. Rev. 2011, 5, 82. [CrossRef] [PubMed]

8. Alizadeh Behbahani, B.; Tabatabaei Yazdi, F.; Vasiee, A.; Mortazavi, S.A. Oliveria decumbens essential oil: Chemical compositions and antimicrobial activity against the growth of some clinical and standard strains causing infection. Microb. Pathog. 2018, 114, 449-452. [CrossRef]

9. Balázs, V.L.; Horváth, B.; Kerekes, E.; Ács, K.; Kocsis, B.; Varga, A.; Böszörményi, A.; Nagy, D.U.; Krisch, J.; Széchenyi, A.; et al. Anti-Haemophilus Activity of Selected Essential Oils Detected by TLC-Direct Bioautography and Biofilm Inhibition. Molecules 2019, 24, 3301. [CrossRef] [PubMed]

10. Ćavar, S.; Maksimović, M.; Vidic, D.; Parić, A. Chemical composition and antioxidant and antimicrobial activity of essential oil of Artemisia annua L. from Bosnia. Ind. Crop. Prod. 2012, 37, 479-485.

11. Fasihi, H.; Noshirvani, N.; Hashemi, M.; Fazilati, M.; Salavati, H.; Coma, V. Antioxidant and antimicrobial properties of carbohydrate-based films enriched with cinnamon essential oil by Pickering emulsion method. Food Packag. Shelf Life 2019, 19, 147-154. [CrossRef]

12. Tang, X.; Shao, Y.-L.; Tang, Y.-J.; Zhou, W.-W. Antifungal Activity of Essential Oil Compounds (Geraniol and Citral) and Inhibitory Mechanisms on Grain Pathogens (Aspergillus flavus and Aspergillus ochraceus). Molecules 2018, 23, 2108. [CrossRef] [PubMed]

13. Stanojevic, L.P.; Marjanovic-Balaban, Z.R.; Kalaba, V.D.; Stanojevic, J.S.; Cvetkovic, D.J. Chemical Composition, Antioxidant and Antimicrobial Activity of Chamomile Flowers Essential Oil (Matricaria chamomilla L). J. Essent. Oil Bear. Plants 2016, 19, 2017-2028. [CrossRef]

14. Alastruey-Izquierdo, A.; Gomez-Lopez, A.; Arendrup, M.C.; Lass-Florl, C.; Hope, W.W.; Perlin, D.S.; Rodriguez-Tudela, J.L.; Cuenca-Estrella, M. Comparison of Dimethyl Sulfoxide and Water as Solvents for Echinocandin Susceptibility Testing by the EUCAST Methodology. J. Clin. Microbiol. 2012, 50, 2509-2512. [CrossRef] [PubMed]

15. Inouye, S.; Tsuruoka, T.; Uchida, K.; Yamaguchi, H. Effect of Sealing and Tween 80 on the Antifungal Susceptibility Testing of Essential Oils. Microbiol. Immunol. 2001, 45, 201-208. [CrossRef] [PubMed]

16. Thielmann, J.; Muranyi, P.; Kazman, P. Screening essential oils for their antimicrobial activities against the foodborne pathogenic bacteria Escherichia coli and Staphylococcus aureus. Heliyon 2019, 5, e01860. [CrossRef]

17. Pina-Barrera, A.M.; Alvarez-Roman, R.; Baez-Gonzalez, J.G.; Amaya-Guerra, C.A.; Rivas-Morales, C.; Gallardo-Rivera, C.T.; Galindo-Rodriguez, S.A. Application of a multisystem coating based on polymeric nanocapsules containing essential oil of Thymus vulgaris L. to increase the shelf life of table grapes (Vitis vinifera L.). IEEE Trans. NanoBiosci. 2019, 549-557. [CrossRef]

18. Zhou, Y.; Sun, S.; Bei, W.; Zahi, M.R.; Yuan, Q.; Liang, H. Preparation and antimicrobial activity of oregano essential oil Pickering emulsion stabilized by cellulose nanocrystals. Int. J. Biol. Macromol. 2018, 112, 7-13. [CrossRef]

19. Abarca, R.L.; Rodríguez, F.J.; Guarda, A.; Galotto, M.J.; Bruna, J.E. Characterization of beta-cyclodextrin inclusion complexes containing an essential oil component. Food Chem. 2016, 196, 968-975. [CrossRef] 
20. Ciobanu, A.; Landy, D.; Fourmentin, S. Complexation efficiency of cyclodextrins for volatile flavor compounds. Food Res. Int. 2013, 53, 110-114. [CrossRef]

21. Cossu, A.; Wang, M.S.; Chaudhari, A.; Nitin, N. Antifungal activity against Candida albicans of starch Pickering emulsion with thymol or amphotericin B in suspension and calcium alginate films. Int. J. Pharm. 2015, 493, 233-242. [CrossRef]

22. Wang, J.; Li, Y.; Gao, Y.; Xie, Z.; Zhou, M.; He, Y.; Wu, H.; Zhou, W.; Dong, X.; Yang, Z.; et al. Cinnamon oil-loaded composite emulsion hydrogels with antibacterial activity prepared using concentrated emulsion templates. Ind. Crop. Prod. 2018, 112, 281-289. [CrossRef]

23. Srivastava, J.K.; Shankar, E.; Gupta, S. Chamomile: A herbal medicine of the past with bright future. Mol. Med. Rep. 2010, 3, 895-901. [PubMed]

24. Rideau, E.; Dimova, R.; Schwille, P.; Wurm, F.R.; Landfester, K. Liposomes and polymersomes: A comparative review towards cell mimicking. Chem. Soc. Rev. 2018, 47, 8572-8610. [CrossRef] [PubMed]

25. Göger, G.; Demirci, B.; Ilgin, S.; Demirci, F. Antimicrobial and toxicity profiles evaluation of the Chamomile (Matricaria recutita L.) essential oil combination with standard antimicrobial agents. Ind. Crop. Prod. 2018, 120, 279-285.

26. Memar, M.Y.; Ghotaslou, R.; Samiei, M.; Adibkia, K. Antimicrobial use of reactive oxygen therapy: Current insights. Infect. Drug Resist. 2018, 11, 567-576. [CrossRef] [PubMed]

27. Eruslanov, E.; Kusmartsev, S. Identification of ROS Using Oxidized DCFDA and Flow-Cytometry. In Advanced Protocols in Oxidative Stress II; Armstrong, D., Ed.; Humana Press: Totowa, NJ, USA, 2010; Volume 594, pp. 57-72. ISBN 978-1-60761-410-4.

28. Dong, T.G.; Dong, S.; Catalano, C.; Moore, R.; Liang, X.; Mekalanos, J.J. Generation of reactive oxygen species by lethal attacks from competing microbes. Proc. Natl. Acad. Sci. USA 2015, 112, 2181-2186. [CrossRef] [PubMed]

29. Máté, G.; Gazdag, Z.; Mike, N.; Papp, G.; Pócsi, I.; Pesti, M. Regulation of oxidative stress-induced cytotoxic processes of citrinin in the fission yeast Schizosaccharomyces pombe. Toxicon 2014, 90, 155-166. [CrossRef]

30. Dohare, S.; Dubey, S.D.; Kalia, M.; Verma, P.; Pandey, H.; Singh, K.; Agarwal, V. Anti-biofilm activity of Eucalyptus globulus oil encapsulated silica nanoparticles against E. coli biofilm. Int. J. Pharm. Sci. Res. 2014, 5, 5013-5018.

31. Saad, N.Y.; Muller, C.D.; Lobstein, A. Major bioactivities and mechanism of action of essential oils and their components: Essential oils and their bioactive components. Flavour Fragr. J. 2013, 28, 269-279. [CrossRef]

32. Horváth, B.; Balázs, V.L.; Horváth, G.; Széchenyi, A. Preparation and in vitro diffusion study of essential oil Pickering emulsions stabilized by silica nanoparticles for Streptococcus mutans biofilm inhibition. Flavour Fragr. J. 2018, 33, 385-396. [CrossRef]

33. Bravo Cadena, M.; Preston, G.M.; Van der Hoorn, R.A.L.; Townley, H.E.; Thompson, I.P. Species-specific antimicrobial activity of essential oils and enhancement by encapsulation in mesoporous silica nanoparticles. Ind. Crop. Prod. 2018, 122, 582-590. [CrossRef]

34. Fujs, S.; Gazdag, Z.; Poljsak, B.; Stibilj, V.; Milacic, R.; Pesti, M.; Raspor, P.; Batic, M. The oxidative stress response of the yeast Candida intermedia to copper, zinc, and selenium exposure. J. Basic Microbiol. 2005, 45, 125-135. [CrossRef] [PubMed]

35. Das, S.; Gazdag, Z.; Szente, L.; Meggyes, M.; Horváth, G.; Lemli, B.; Kunsági-Máté, S.; Kuzma, M.; Kőszegi, T. Antioxidant and antimicrobial properties of randomly methylated $\beta$ cyclodextrin-Captured essential oils. Food Chem. 2019, 278, 305-313. [CrossRef] [PubMed]

36. Stromájer-Rácz, T.; Gazdag, Z.; Belágyi, J.; Vágvölgyi, C.; Zhao, R.Y.; Pesti, M. Oxidative stress induced by HIV-1 F34IVpr in Schizosaccharomyces pombe is one of its multiple functions. Exp. Mol. Pathol. 2010, 88, 38-44. [CrossRef]

37. Gazdag, Z.; Máté, G.; Čertik, M.; Türmer, K.; Virág, E.; Pócsi, I.; Pesti, M. tert-Butyl hydroperoxide-induced differing plasma membrane and oxidative stress processes in yeast strains BY4741 and erg5 $\Delta$ : t-BuOOH-induced cytotoxic processes in yeast. J. Basic Microbiol. 2014, 54, S50-S62. [CrossRef]

38. Henderson, L.M.; Chappell, J.B. Dihydrorhodamine 123: A fluorescent probe for superoxide generation? Eur. J. Biochem. 1993, 217, 973-980. [CrossRef]

39. Appiah, T.; Boakye, Y.D.; Agyare, C. Antimicrobial Activities and Time-Kill Kinetics of Extracts of Selected Ghanaian Mushrooms. Evid. Based Complement. Altern. Med. 2017, 2017,1-15. [CrossRef] 
40. Moscho, A.; Orwar, O.; Chiu, D.T.; Modi, B.P.; Zare, R.N. Rapid preparation of giant unilamellar vesicles. Proc. Natl. Acad. Sci. 1996, 93, 11443-11447. [CrossRef]

Sample Availability: Samples of the compounds chamomile EO and SNPs are available from the authors. 